\title{
PENINGKATAN KEMAMPUAN MENULIS KARANGAN MENGGUNAKAN MEDIA KARTU PENUNTUN (KP) PEMBELAJARAN BAHASA INDONESIA SISWA KELAS V SD MUHAMMADIYAH 08 DAU MALANG
}

\author{
Vivi Megasari
}

\begin{abstract}
Students in grade V to SD Muhammmadiyah 08 Dau Malang have difficult in learning the language Indonesia. Many students have not reached a specified standart of completeness and the school has not been able to write a good esay. Abstract material is still difficult to understand by students. Students just tend to write but do not know process, students are difficult to obtain values corresponding to the KKM. The research alms to improve students skill in writing essay by using card media guide (KP). Media card guide consists of 4 parts, namely the theme of the card, the type of essay, question, and corrections. This research alms to improve students skill in writing essay by using a media cardguide (KP) so as to achieve the specified schools criteria. Exhaustivences school minimum used in the school is 76,00. Type of study is classroom with research designmodel of Kemmis and Mc. Taggart. Subject and placein study werestudents in garde V SDMuhammadiyah 08 Dau Malang with 31 students comprising 14 boys and 17 girls. According to the achievement of the purpose of this study conducted in two cycles. Data in the study of data obtained from observations, interviews, documentation and testing. The results ofthis studyindicatethe cycleI56.7\% studentsachieve exhaustivenessinwritingthe essay was not finisied in $43.3 \%$. To write cycle II $88,6 \%$ an increase in the ability of studens to write esay. This proves that the use of card media guide (KP) can improve the ability understanding of studens in essay writing and create a pleasant learning situation. This study recommends the Indonesian teaching essay writing should use the guiding cards (KP) as medium of learning and more inovatif in learning developing the Guide Card (KP).
\end{abstract}

\begin{abstract}
Abstrak: Siswa kelas V SD Muhammadiyah 08 Dau Kabupaten Malang mengalami kesulitan pada materi menulis karangan pada pelajaran Bahasa Indonesia. Banyak siswa belum mencapai standar ketuntasan yang ditentukan sekolah dan belum bisa menulis karangan dengan baik dan benar. Sifat materi yang bersifat abstrak siswa sulit untuk memahami.Siswa hanya cenderung menulis tetapi tidak mengetahui konsep yang benar. Kurangnya media dan alat peraga untuk mendukung proses pembelajaran, siswa sulit untuk memperoleh nilai yang sesuai dengan KKM. Penelitian ini bertujuan untuk meningkatkan kemampuan siswa dalam menulis karangan dengan menggunakan media Kartu Penuntun (KP). Media kartu Penuntun (KP) terdiri atas 4 bagian yaitu kartu tema, jenis karangan. pertanyaan, dan koreksi. Penelitian ini bertujuan untuk meningkatkan kemampuan siswa dalam menulis karagan dengan menggunakan media Kartu Penuntun (KP) sehingga mencapai kriteria ketuntasan yang ditentukan sekolah. Kriteria ketuntasan minimum yang digunakan di sekolah tersebut adalah 76.00. Jenis penelitian ini adalah penelitian tindakan kelas dengan desain penelitian model Kemmis dan Mc. Taggart. Subjek dan tempat dalam penelitian adalah siswa kelas VA SD Muhammadiyah 08 Dau Kabupaten Malang dengan jumlah 31 siswa yang terdiri 14 siswa laki-laki dan 17 siswa perempuan. Sesuai dengan ketercapaian tujuan penelitian ini dilakukan dalam 2 siklus. Data-data dalam penelitian diperoleh dari hasil observasi, wawancara, dokumentasi, dan tes. Analisis data dilakukan secara diskriptif kualitatif Hasil penelitian ini menunjukkan pada siklus I 56,7\% siswa mencapai ketuntasan dalam menulis karangan dan $43,3 \%$ belum tuntas dalam menulis karangan. Pada siklus
\end{abstract}




\begin{abstract}
II 88,6 \% siswa mencapai ketuntasan dalam menulis karangan dan 13,3\% belum tuntas dalam menulis karangan. Dalam siklus II terjadi peningkatan dalam kemampuan siswa menulis karangan. Hal ini membuktikan bahwa penggunanaan media Kartu Penuntun (KP) dapat meningkatkan kemampuan, pemahaman siswa dalam menulis karangandan menciptakan suasana pembelajaran yang menyenangkan. Penelitian ini merekomendasikan dalam mengajarkan menulis karangan bahasa Indonesia hendaknya menggunakan Kartu Penuntun (KP) sebagai media pembelajaran dan lebih inovatif dalam mengembangkan Kartu Penuntun (KP).
\end{abstract}

Kata Kunci: pembelajaran menulis karangan, media kartu penuntun (KP)

\section{PENDAHULUAN}

Pembelajaran bahasa Indonesia merupakan pembelajaran yang paling utama. Dikatakan demikian karena dengan bahasa siswa dapat menimba ilmu pengetahuan, teknologi, seni, serta informasi yang ditularkan oleh pendidik. Proses tersebut terjadi sejak awal belajar di sekolah (Santoso, 2003:13).

Pelajaran bahasa Indonesia berdasarkan standar kompetensi dan kompetensi dasar yang terdapat pada kurikulum KTSP mempunyai tujuan, antara lain: (1) Sarana pembinaan persatuan dan kesatuan bangsa; (2) Sarana peningkatan pengetahuan dan keterampilan dalam rangka pelestarian dan pengembangan budaya; (3) Sarana peningkatan pengetahuan dan keterampilan untuk meraih dan mengembangkan ilmu pengetahuan, teknologi, dan seni; (4) Sarana penyebarluasan pemakaian bahasa Indonesia yang baik untuk berbagai keperluan menyangkut berbagai masalah; (5) Sarana pengembangan penalaran; (6) Sarana pemahaman beragam budaya Indonesia melalui khasanah kesusastraan Indonesia (Pusat Kurikulum Balitbang Depdiknas : 2003:1).

Tujuan tersebut jelas tergambar bahwa fungsi pengajaran bahasa Indonesia di SD adalah sebagai wadah untuk mengembangkan kemampuan siswa dalam menggunakan bahasa sesuai dengan fu- ngsi bahasa itu, terutama sebagai alat komunikasi. Pembelajaran bahasa Indonesia di SD mengacu pada tujuan pembelajaran bahasa Indonesia dengan mengacu pada tujuan maka akan membentuk suatu pola pikir siswa mengenai pembelajaran bahasa Indonesia yang baik dan benar. Pembentukan pola pikir siswa dipengaruhi oleh perkembangan bahasanya.

Kemampuan menulis anak dipengaruhi oleh perkembangan bahasanya. Dengan menulis anak dapat mengetahui dan mengenali kemampuan dan potensi diri. Anak dapat mengetahui sampai mana pengetahuan tentang topik yang akan dibahas dalam suatu tulisan. Mengemba ngkan gagasan menjadikan anak selalu mencari informasi-informasi mengenai topik yang sedang dibahas. Mengorganisasikan gagasan dan menilai gagasan sendiri secara obyektif akan mempermudah menganalisis masalah secara tersurat, mendorong belajar secara aktif, dan membiasakan berpikir berbahasa secara tertib.

Kemampuan menulis merupakan kemampuan yang kompleks yang menuntut sejumlah pengetahuan dan keterampilan. Menulis suatu karangan sederhana diperlukan standar penulisan yang sama dengan standar penulisan karangan yang rumit. Standar dalam menulis harus memilih topik, membatasi topik, mengembangkan gagasan, menyajikan dalam 
kal kalimat, paragraf yang logis dan sebagainya.

Kemampuan siswa dalam mengolah kata menjadi karangan yang sudah sedikit dipahami perlu ditingkatkan apalagi siswa pada tingkat pendidikan dasar kelas rendah. Kemampuan siswa dalam merangkai kata menjadi sebuah karangan dengan pola kalimat yang benar dan tepat merupakan dasar kelas rendah. Untuk memicu kemampuan siswa dalam merangkai kata menjadi karangan yang benar dan baik diperlukan adanya kreativitas guru. Salah satu alat pemicu adalah dengan adanya kegiatan belajar dan mengajar yang menarik bagi siswa. Siswa pada tingkat pendidikan dasar lebih cenderung senang dengan hal-hal yang baru dan menarik. Untuk menarik perhatian siswa dalam kegiatan belajar diperlukan adanya sesuatu yang baru dan berbeda dari sebelumnya.

Pelajaran bahasa kelas V SD/MI materi pokok tentang menulis secara konseptual materi ini bermanfaat untuk memberikan pemahaman tentang pentingnya menulis yang baik dan benar. Siswa diharapkan dapat menulis karangan dengan baik dan benar, sesuai dengan ketentuan dalam bahasa Indonesia. Berdasarkan temuan di lapangan banyak siswa kelas V SD Muhammadiyah 08 Dau Kabupaten Malang yang kesulitan menulis karangan pada semester I tahun pelajaran 2011/2012 pada pelajaran bahasa Indonesia dengan materi yang berhubungan dengan menyusun karangan. Berdasarkan wawancara dengan guru kelas pada pelajaran bahasa Indonesia banyak siswa SD Muhammadiyah 08 Dau Kabupaten Malang yang nilainya belum mencapai standar ketuntasan belajar dengan KKM 76,00 dan ketuntasan klasikal sekolah sebesar 70\%. Data yang diperoleh menunjukkan bahwa dari 31 siswa terdapat 5 siswa yang nilainya diatas standar ketuntasan atau 16,7\% dan 26 siswa belum mencapai standar ketuntaasan atau $16,7 \%$. Menurut para guru kondisi demikian disebabkan antara lain: (1) Kurangnya kretifitas dan inovasi dalam mengelola pembelajaran membuat siswa merasa bosan dalam mengikuti pelajaran sehingga berpengaruh dalam pencapaian hasil belajar siswa; (2) Sifat materi yang bersifat abstrak sehingga siswa sulit untuk memahami. Siswa hanya cenderung membuat tetapi tidak mengetahui konsep yang benar. Agar siswa dapat mengemukakan pendapat atau gagasan dengan baik diperlukan suatu rangsangan atau stimulus yang konkrit sehingga siswa dapat mengembangkan ide dan gagasan yang mereka temukan; (3) Kurangnya penggunaan metode-metode yang bervariasi karena penggunaan metode yang tidak bervariasi akan membuat siswa bosan; (4) Kurangnya med media dan alat peraga untuk mendukung proses pembelajaran, sehingga siswa sulit untuk memperoleh nilai yang sesuai dengan $\mathrm{K}$ KM.

Uraian di atas menunjukkan bahwa dalam pembelajaran menulis karangan banyak siswa yang kurang paham. Kurangnya pemahaman siswa berpengaruh pada hasil belajar yang masih belum mencapai standar yang ditentukan sekolah. Pembelajaran yang baik adalah pembelajaran yang menyenangkan. Salah satu cara agar siswa menjadi semangat dan mudah memahami yaitu dengan cara belajar dengan sesuatu hal yang baru yang akan memicu semangat siswa untuk mengetahuinya. Salah satu hal yang baru adalah belajar menggunakan Kartu Penuntun. Kartu Penuntun adalah kartu yang berisi petunjuk dalam membuat karangan. Petunjuknya berupa pertanyaanpertanyaan yang akan mempermudah siswa dalam membuat kerangka karangan. Kartu Penuntun ini terdiri atas empat 
bagian yaitu kartu tema yaitu kartu yang berisi tema dalam menulis karangan, kartu jenis karangan berisi jenis-jenis karangan sehingga siwa dapat memilih jenis karangan apa yang akan dibuat, kartu pertanyaan kartu yang berisi pertanyaanpertanyaan yang jawabanya akan membentuk kerangka karangan, dan kartu koreksi yang isinya perintah untuk memeksa ejaan, tanda baca, dan pilihan kata. Kartu Penuntun akan mempermudah siswa mengembangkan imajinasinya dalam membuat karangan. Kartu Penuntun ini dapat digunakan dalam model pembelajaran kelompok atau individu.

Tujuan utama penggunaan Kartu Penuntun ini adalah memicu siswa agar dapat menulis dengan benar sehingga siswa dapat membuat karangan yang baik dan benar. Penggunaan kartu ini secara tidak langsung akan mengajarkan pada siswa untuk membuat karangan. Berdasarkan pemikiran tersebut, maka digunakan media Kartu Penuntun untuk meningkatkan kemampuan siswa kelas $\mathrm{V}$ di SD Muhammadiyah 08 Dau dalam mengarang dengan judul "Peningkatan Kemampuan Menulis Karangan Menggunakan Media Kartu Penuntun (KP) Pembelajaran Bahasa Indonesia Siswa Kelas V SD Muhammadiyah 8 Dau Malang”.

\section{KAJIAN PUSTAKA}

\section{Tahap-tahap Perkembangan Bahasa Anak SD}

Usia anak kelas V SD memasuki tahap semantik. Mereka sudah menguasai banyak kosakata yang memungkinkan anak lebih mudah memahami wacana dan menemukan makna kata berdasarkan konteksnya. Anak sudah mampu mengembangkan dan merangkai kata-kata sehingga membentuk sebuah makna yang lebih luas. Apabila dihubungkan dengan pelajaran menulis yang dilaku- kan pada siswa kelas V SD, anak diharapkan mampu menulis karangan karena mereka sudah memiliki banyak perbendaharaan kosakata yang memungkinkan mereka lebih mudah menuangkan ide.

\section{Pembelajaran Bahasa Indonesia di Sekolah Dasar (SD)}

Pembelajaran bahasa Indonesia SD merupakan pembelajaran yang paling $\mathrm{u}-$ tama, terutama di SD kelas rendah (I dan II), maupun kelas tinggi (III-VI). Dikatakan demikian karena dengan bahasa siswa dapat menimba ilmu pengetahuan, teknologi, seni, serta informasi yang ditularkan dari pendidik. Proses tersebut terjadi sejak awal sekolah. Mencermati hal tersebut, maka guru sebagai pelaksana dan pengelola pembelajaran di sekolah dituntut untuk dapat merancang, melaksanakan, dan mengevaluasi aspekaspek yang tercakup dalam pembelajaran bahasa Indonesia.

Telah dirumuskan secara nasional bahwa bahasa Indonesia dikembangkan melalui empat aspek keterampilan utama yakni menyimak, berbicara, membaca dan menulis (Santoso, 2003: 13). Aspekaspek keterampilan bahasa Indonesia dalam setiap pertemuan (tatap muka) ditetapkan satu aspek sebagai fokus. Keempat aspek keterampilan berbahasa itu merupakan satu kesatuan yang tidak terpisahkan dan saling menunjang.

\section{Konsep Dasar Pembelajaran Menulis}

Menulis merupakan suatu keterampilan berbahasa yang dipergunakan untuk berkomunikasi secara tidak langsung dan tidak tatap muka. Keterampilan menulis tidak akan datang secara otomatis melainkan harus melalui latihan dan pratik yang banyak dan teratur Tarigan dalam Korib (2005: 16). Sujanto (dalam Korib Farhan 2005: 16) mengungkapkan 
bahwa menulis merupakan salah satu keterampilan berbahasa yang dilandasi dengan pengetahuan kebahasaan dan menulis juga merupakan suatu proses yang tidak mungkin datang tanpa adanya latihan.

Menurut Lado (dalam Korib Farhan 2005: 16) menulis adalah meletakkan atau mengatur simbol-simbol grafis yang menyatakan pemahaman suatu bahasa sedemikian rupa sehingga orang lain dapat membaca simbol-simbol grafis itu, sebagai penyajian satuan-satuan ekspresi bahasa. Menurut Akhadiah (dalam Korib Farhan 2005:16) menulis adalah suatu kegiatan penyampaian pesan dengan menggunakan bahasa sebagai mediumnya. Pesan adalah isi atau muatan yang terkandung dalam tulisan.

Kesimpulan dari berbagai pendapat diatas adalah menulis merupakan suatu kegiatan untuk menyampaikan suatu pesan kepada orang lain dengan medium bahasa yang telah disepakati bersama da$\mathrm{n}$ tidak secara tatap muka.

\section{Media Pembelajaran}

Kata media berasal dari bahasa latin medius yang secara harfiah berarti "tengah" perantara atau pengantar. Dalam bahasa Arab media adalah perantara atau pengantar pesan dari pengirim kepada penerima. Menurut Gerlach dan Ely (dalam Arsyad, 2010: 3) media adalah manusia atau kejadian yang membangun kondisi dan membuat siswa memperoleh pengetahuan, keterampilan, atau sikap.

Hainich, dan kawan-kawan (dalam Arsyad, 2010: 4) mengemukakan istilah medium sebagai perantara yang mengatur informasi antara sumber dan penerima. Hamidjojo dalam Lutuheru (dalam Arsyad, 2010:4) memberi batasan media sebagai semua bentuk perantara yang digunakan oleh manusia untuk menyebar- kan ide, gagasan, atau pendapat sehingga ide, gagasan, atau pendapat yang dikemukakan itu sampai kepada penerima yang dituju.

Beberapa penjelasan di atas dapat disimpulkan bahwa media adalah sarana alat bantu mengajar. Teknik, metode, dan sarana prasarana lain termasuk dukungan lingkungan untuk menciptakan komunikasi untuk penyampaian pesan pembelajaran dengan berhasil sebagaimana yang telah direncanakan oleh guru.

\section{Kartu Penuntun (KP)}

Dalam kamus bahasa Indonesia kartu adalah selembar kertas yang tak seberapa besar biasanya persegi panjang untuk berbagai keperluan. Sedangkan penuntun adalah petunjuk untuk melakukan suatu pekerjaan. Kartu Penuntun adalah kartu yang berisi petunjuk.

Kartu Penuntun terdiri dari empat bagian yaitu: kartu pertama merupakan kartu tema berisi tentang tema karangan, kartu kedua merupakan kartu jenis karangan berisi jenis-jenis karangan, kartu ke tiga merupakan kartu pertanyaan berisi pertanyaan pembuka, isi, dan penutup, dan kartu keempat adalah kartu koreksi yang berisi ejaan, tanda baca, dan pilihan kata. Penggunaan Kartu Penuntun dapat secara berkelompok atau individu.

\section{METODE}

Penelitian ini menggunakan jenis penelitian tindakan kelas. Penelitian tindakan kelas (PTK) adalah penelitian yang dilakukan oleh guru dikelasnya sendiri dengan cara (1) merencanakan, (2) me laksanakan dan, (3) merefleksikan tindakan secara kolaboratif dan partisipatif dengan tujuan memperbaiki kinerjanya sebagai guru, sehingga hasil belajar sis- 
wa dapat meningkat ( Kusuma dan Dedi, 2010: 9).

Menurut Carr dan Kemmis (dalam, Kusuma dan Dedi, 2010: 8) hakikat penelitian tindakan kelas adalah suatu bentuk penelitian refleksi diri (self reflective) yang dilakukan oleh para partisipan dalam situasi sosial untuk memperbaiki rasionalitas dan kebenaran. Berdasarkan pengertian di atas maka dapat diambil kesimpulan bahwa penelitian tindakan kelas merupakan penelitian yang dilakukan oleh guru guna memperbaiki kinerjanya sebagai seorang pendidik agar hasil belajar siswa dapat meningkat.

Penelitian ini menggunakan model Kemmis dan Mc. Taggart. Model ini tindakan dan pengamatan dijadikan satu kesatuan. Disatukannya kedua komponen tersebut disebabkan oleh adanya kenyataan bahwa antara penerapan tindakan dan pengamatan merupakan dua kegiatan yang tidak dapat dipisahkan. Bentuk desain Kemmis dan Mc. Taggart

Teknik pengumpulan data dalam penelitian ini menggunakan observasi. Penelitian ini jika dilihat dari segi proses pelaksanaannya merupakan participant observation karena terlibat langsung dalam aktivitas siswa dan jika dilihat dari segi instrumentasi yang digunakan adalah observasi terstruktur karena observasi telah dirancang secara sistematis. Teknik yang kedua adalah dokumentasi. Dalam penelitian ini dokumentasi yang digunakan agar mengetahui data-data siswa dan nilai siswa sebelum melakukan penelitian. wawancara dengan guru kelas sehingga penulis memperoleh informasi tentang siswa yang akan diteliti. Data yang diperoleh dari wawancara dengan guru kelas adalah banyak siswa kelas V SD Muhammadiyah 08 Dau Kabupaten Malang yang nilainya belum mencapai standar ketuntasan yang ditentukan sekolah. Selanjutnya tes. Dalam penelitian ini menggunakan tes subyektif. Nilai dalam tes subyektif diperoleh dari hasil menulis karangan yang telah dilakukan siswa. Indikator proses pembelajaran dilihat dari: kognitif, afektif, psikomotorik.

Analisa data yang dilakukan untuk teknik tes menggunakan analisa data kuantitatif. Sedangkan untuk menjelaskan data-data yang diperoleh menggunakan analisa data diskriptif kualitatif.

\section{HASIL DAN PEMBAHASAN}

Dalam proses pembelajaran pada siklus I masih ada beberapa hal yang perlu diperbaiki yaitu pengelolaan waktu, pemberian materi tentang ejaan, tanda baca, dan pilihan kata yang masih kurang jelas sehingga, metode kelompok yang kurang efektif, penjelasan mengenai jenis-jenis karangan yang belum disampaikan dan media pembelajaran yang terbatas jumlahnya. Untuk siswa sudah aktif namun masih perlu ditingkatkan agar siswa juga bisa lebih baik lagi. Sedangkan pada siklus II sudah bagus dalam kegiatan belajar mengajar baik ketika menyampaikan materi, mengkondisikan kelas, dan penggunaan media pembelajaran. Media pembelajaran yang digunakan juga menarik siswa dalam kegiatan pembelajaran. Dalam pembelajaran siswa juga sudah aktif. Terlihat perbandingan dari pelaksanaan siklus I dan siklus II, yang sudah dilakukan perbaikan dari pelaksanaan siklus I terlihat terjadi peningkatan dalam kegiatan belajar mengajar pada siklus II baik oleh guru maupun siswa. Hal ini menunjukkan bahwa memedia Kartu Penuntun dapat meningkatkan kemampuan siswa dalam menulis karangan

Hasil diskusi dalam penelitian menunjukkan bahwa media Kartu Penuntun memudahkan siswa dalam menulis karangan serta memudahkan berimajinasi da$\mathrm{n}$ bernalar untuk menemukan ide dalam menulis karangan dibuktikan pada siklus 
II ketika menggunakan Kartu Penuntun menunjukkan ketuntasan siswa mencapai lebih dari standar ketuntasan klasikal yang ditentukan sekolah yaitu $70 \%$. Media Kartu Penuntun ini bermanfaat dalam pembelajaran mengarang sehingga perlu dikembangkanlagi. Peningkatan kemampuan mengarang siswa dengan menggunakan media Kartu Penuntun.

\section{KESIMPULAN}

Berdasarkan prosedur dan hasil penelitian yang telah dilakukan dapat diperoleh data bahwa pada siklus I kriteria ketuntasan minimal dalam pelajaran bahasa Indonesia belum tercapai sedangkan pada siklus II kriteria ketuntasan sudah tercapai. Tejadi peningkatan nilai siswa dalam mengarang pada siklus II. Sehingga dapat dikatakan bahwa penggunaan Kartu Penuntun (KP) dapat meningkatkan kemampuan siswa dalam me nulis karangan.

Pembahasan hasil penelitian menyimpulkan bahwa media pembelajaran Kartu Penuntun dapat meningkatkan kemampuan siswa dalam mengarang khususnya siswa kelas V SD Muhammadiyah 08 Dau, penggunaan media pembelajaran Kartu Penuntun dapat menciptakan suasana belajar yang menyenangkan khususnya siswa kelas V SD Muhammadiyah 08 Dau, dan penggunaan media pembelajaran Kartu Penuntun dapat meningkatkan pemahaman siswa tentang materi menulis karangan dalam mata pelajaran bahasa Indonesia kelas V SD Muhammadiyah 08 Dau.

\section{DAFTAR PUSTAKA}

Apud. 2003. Jenis Karangan, (online). / 2008/04/23/Jenis-jenis-Kara ngan), diakses 14 Oktober 2011.
Arsyad, Azhar. 2010. Media Pembelajaran. Jakarta: Rajawali Pres.

Faisal, dkk. 2010. Kajian Bahasa Indonesia. Malang: Direktorat Jendral Pendidikan Tinggi Kementrian Pendidikan Nasional.

Farhan, Korib. 2005. Hakekat Kalimat, (online), //www.Scribd.Com/doc / 29013517/9/ Hakikat- Menulis), diakses 20 januari 2012.

Ginting, Abdorrakhman. 2008. Belajar dan Pembelajaran. Bandung: Humoniora.

Hairuddin,dkk. 2008. Pembelajaran Bahasa Indonesia. Jakarta: Direktorat Jendral Pendidikan Tinggi Departemen Pendididkan Nasional.

Hasbullah. 2010. Dasar-Dasar Ilmu Pendidikan. Jakarta: PT. Raja grafindo Persada.

Jihat, Asep dan Abdul Haris. 2009. Evaluasi Pembelajaran. Yogyakarta: Multi Press.

Kusumah,wijaya, dan Dedi Dwitagama. 2010. Mengenal Penulisan Tindakan Kelas. Jakarta: PT. indeks.

Lestari, Nurdiana. 2010. Perkembangan Bahasa Anak. (online), (http://edukasi.kompasiana.com/2010/12/per kembangan-bahasa-dalam-usia-anak-sd/), diakses 26 Desember2011.

Lintang, Sri. 2011. Peningkatan Kemampuan Menulis Karangan Bahasa Indonesia Melalui Media Gambar Berseri Siswa Kelas IV SD Muhammadiyah 08 Dau Kabupaten Malang. Malang: UMM.

Muslich, Masnur. 2009. Melaksanakan PTK Itu Mudah. Malang: Bumi Aksara.

Poerwanti, dkk. 2011. Pedoman Penulisan Skripsi. Malang: UMM.

Priyadi,Benny.2009. Model Desain Sistem Pembelajaran. Jakarta: Dian Rakyat. 
Pusat Kurikulum Balitbang tahun 2003 tentang Standar Kompetensi Mata Pelajaran Bahasa Indonesia. Depdiknas, (online), (http: //rumahinspirasi.com/wpcontent/upload/2009 /08/bahasa Indonesia. Pdf), diakses 3 april 2012.

Santoso, Puji. 2003. Materi Pembelajaran Bahasa Indonesia SD. Jakarta: Pusat Penerbitan Universitas Terbuka.

Sofeyah. 2009. Peningkatan Kemampuan Menulis Permulaan Melalui Media Kartu Huruf di Kelas I SDN Karangsentul I Kecamatan Gondang Wetan Kabupaten Pasuruan. Malang: UM.

Sugiono. 2009. Metode Penulisan Pendidikan. Bandung: Alfabeta.

Sumigyo, Heri. 2008. Bahasa Indonesia Keilmuan. Malang: UMM Pres.

Suparno, dan Muhammad Yunus. 2002. Keterampilan Dasar Menulis. Jakarta: Pusat Penerbitan Universitas Terbuka.

Tim Dosen. 2003. Bahasa Indonesia untuk Karangan Imiah. Malang: UMM Pres.
Tim Pustaka Phoenix. 2007. Kamus Besar Bahasa Indonesia Edisi baru. Jakarta: Phoneix.

Wawan, 2010. Manfaat Menulis, (online), News.aspx?id =18374), diakses 15 mei 2011. 